\title{
Supercritical water oxidation of phenol and process enhancement with in situ formed $\mathrm{Fe}_{2} \mathrm{O}_{3}$ nano catalyst
}

\author{
Ammar Al-Atta ${ }^{1,2} \cdot$ Farooq Sher $^{3}$ (D) Abu Hazafa ${ }^{4,5} \cdot$ Ayesha Zafar $^{4,6} \cdot$ Hafiz M. N. Iqbal $^{7}$. \\ Emina Karahmet ${ }^{8} \cdot$ Edward Lester $^{1}$
}

Received: 14 May 2021 / Accepted: 3 September 2021 / Published online: 24 September 2021

(C) The Author(s) 2021

\begin{abstract}
During the past few decades, the treatment of hazardous waste and toxic phenolic compounds has become a major issue in the pharmaceutical, gas/oil, dying, and chemical industries. Considering polymerization and oxidation of phenolic compounds, supercritical water oxidation (SCWO) has gained special attention. The present study objective was to synthesize a novel in situ $\mathrm{Fe}_{2} \mathrm{O}_{3}$ nano-catalyst in a counter-current mixing reactor by supercritical water oxidation (SCWO) method to evaluate the phenol oxidation and COD reduction at different operation conditions like oxidant ratios and concentrations. Synthesized nano-catalyst was characterized by powder X-ray diffraction (XRD) and transmission electron microscope (TEM). TEM results revealed the maximum average particle size of 26.18 and $16.20 \mathrm{~nm}$ for preheated and non-preheated oxidant configuration, respectively. XRD showed the clear peaks of hematite at a $2 \theta$ value of $24,33,35.5,49.5,54,62$, and 64 for both catalysts treated preheated and nonpreheated oxidant configurations. The maximum COD reduction and phenol oxidation of about $93.5 \%$ and $99.9 \%$ were observed at an oxidant ratio of $1.5,0.75 \mathrm{~s}, 25 \mathrm{MPa}$, and $380{ }^{\circ} \mathrm{C}$ with a non-preheated $\mathrm{H}_{2} \mathrm{O}_{2}$ oxidant, while in situ formed $\mathrm{Fe}_{2} \mathrm{O}_{3}$ nano-catalyst showed the maximum phenol oxidation of $99.9 \%$ at $0.75 \mathrm{~s}, 1.5$ oxidant ratio, $25 \mathrm{MPa}$, and $380{ }^{\circ} \mathrm{C}$. Similarly, in situ formed $\mathrm{Fe}_{2} \mathrm{O}_{3}$ catalyst presented the highest COD reduction of $97.8 \%$ at $40 \mathrm{mM}$ phenol concentration, 1.0 oxidant ratio, $0.75 \mathrm{~s}$ residence time, 380 ${ }^{\circ} \mathrm{C}$, and $25 \mathrm{MPa}$. It is concluded and recommended that SCWO is a feasible and cost-effective alternative method for the destruction of contaminants in water which showed the complete conversion of phenol within less than $1 \mathrm{~s}$ and 1.5 oxidant ratio.
\end{abstract}

Keywords Environmental management $\cdot$ Supercritical water oxidation $\cdot$ Nanoparticles $\cdot$ Fenton reactions $\cdot$ Hematite $\cdot$ Phenol $\cdot$ Counter current mixing reactor $\cdot$ Wastewater treatment

\section{Introduction}

During the past few decades, wastewater purification and treatment has gained special attention due to global water

Responsible Editor: Ricardo A. Torres-Palma

Farooq Sher

Farooq.Sher@ntu.ac.uk

1 Department of Chemical and Environmental Engineering, University of Nottingham, University Park, Nottingham NG7 2RD, UK

2 Oil and Gas Refinery Department, Al-Farabi University College, Baghdad, Iraq

3 Department of Engineering, School of Science and Technology, Nottingham Trent University, Nottingham NG11 8NS, UK scarcity and environmental pollution. Organic wastewater is considered most hazardous due to its poor biodegradability and high salinity that comes from pharmaceutical, oil/gas, petroleum, pesticide, textile, chemical, and dyeing industries

4 International Society of Engineering Science and Technology, Nottingham, UK

5 Department of Biochemistry, University of Agriculture, Faisalabad 38040, Pakistan

6 Institute of Biochemistry and Biotechnology, Faculty of Biosciences, University of Veterinary and Animal Sciences, Lahore, Pakistan

7 Tecnologico de Monterrey, School of Engineering and Sciences, 64849 Monterrey, Mexico

8 Department of Biochemistry, Faculty of Pharmacy, University of Modern Science, 88000 Mostar, Bosnia and Herzegovina 
(Zhang et al. 2020b). The emerging evidence revealed that phenol and its derivates (ortho-(ethoxymethyl)-phenol, 2methoxy-4-methyl-phenol, resorcinol, and guaiacol) are ranked as one of the highly toxic organic compounds globally by the United States Environmental Protection Agency (USEPA) due to their several health concerns including carcinogenic and teratogenic effects (Ren et al. 2018, Ren et al. 2017). However, the concentration of phenolic waste continues to increase in response to accelerated urbanization and industrialization. Therefore, some physiochemical techniques are required to remove organic content and break a ring-shaped phenol structure from wastewater (Zhang et al. 2020a).

Traditionally different strategies such as coagulation, adsorption, membrane separation, and incineration methods have been employed for the treatment of toxic and hazardous wastewater to remove organic and inorganic pollutants. These techniques were used to destroy hazardous waste or convert them into non-hazardous materials such as antacids. However, all of these techniques are limited to desire outcomes due to their high cost; hazardous stack gas emissions such as NOx, dioxin, and furan, low concentration waste, relatively longer residence time, and reactor volumes (Fang \& Xu 2014, Lin \& Ma 2012). The conventionally most applied microbial method is also limited to phenolic wastewater treatment due to the delocalization of $\pi$ bond in the phenolic ring. Nevertheless, long-term discharge and treatment difficulties of phenolic wastewater could lead to more discharge of industrial waste on the water surface that is a serious problem for not only the human health but also the ecosystem. However, an alternative strategy should be adopted to treat phenolic wastewater (Pillai \& Gupta 2016, Zhang et al. 2019).

During last few years, supercritical water oxidation (SCWO) technique has gained extensive consideration in the treatment of organic wastewater because of high ion mass, low dielectric constant, and low density. Accumulated data revealed that $\mathrm{SCW}$ used oxidant gases $\left(\mathrm{O}_{2}, \mathrm{O}_{3}\right.$, and $\left.\mathrm{NO}_{2}\right)$, non-polar properties of water above its critical point $\left(22.1 \mathrm{MPa}\right.$ and $\left.374{ }^{\circ} \mathrm{C}\right)$, and non-polar hydrocarbons to develop a single phase. SCWO has advantages over conventional reported waste treatment techniques due to its efficiency and environmentally friendly behavior (Kıpçak \& Akgün 2012, Zhao et al. 2020). The destruction of organic compounds in SCWO is primarily based upon radical reaction mechanisms rather than ionic reactions due to very low values of the ionic product of water at supercritical conditions. The organic molecules are attacked by free radicals which are produced during the oxidation of organic compounds in SCW (see Eqs. (1-3) (Fang \& Xu 2014)).

Hydroxyl generation:

$\mathrm{H}_{2} \mathrm{O}_{2} \rightarrow 2 \mathrm{HO}$
Hydrogen removal and generation of organic radical (R'):

$\mathrm{RH}+\mathrm{HO}^{*} \rightarrow \mathrm{R}^{\cdot}+\mathrm{H}_{2} \mathrm{O}$

Production of peroxy radical (ROO'):

$\mathrm{R}+\mathrm{O}_{2} \rightarrow \mathrm{ROO}$

Peroxy radical (ROO') extracts a hydrogen atom to form an organic peroxide $(\mathrm{ROOH})$ and a new organic radical ( $\left.\mathrm{R}^{\prime}\right)$. Generally, different oxidant including air, $\mathrm{O}_{2}$, and $\mathrm{H}_{2} \mathrm{O}_{2}$ are applied into the superheated water during supercritical water oxidation (SCWO) that not only increase the operational cost but also enhance energy demand $\left(500-700{ }^{\circ} \mathrm{C}\right.$ ) (Huelsman and Savage, 2013, Zhang et al. 2020a). However, the proper usage of catalysts could effectively improve the oxidant concentration and reactor energy demand without affecting the operational performance (Xu et al. 2020). An appropriate catalyst not only improves the removal of chemical oxygen demand (COD) of the waste but also enhances the selectivity of phenols into $\mathrm{CO}_{2}, \mathrm{CH}_{4}$, and $\mathrm{H}_{2}$ (Nadjiba et al. 2017). Recently, different heterogeneous catalysts including $\mathrm{V}_{2} \mathrm{O}_{5} / \mathrm{Al}_{2} \mathrm{O}_{3}$, $\mathrm{MnO}_{2} / \mathrm{CeO}_{2}, \mathrm{TiO}_{2}$, Caroline $150, \mathrm{CuO} / \mathrm{ZnO} / \mathrm{CoO}$, and $\mathrm{MnO}_{2}$ have been used by different researchers for phenol oxidation (Abdpour and Santos, 2020, De Silva et al. 2017, Huelsman and Savage, 2013).

Top et al. (2020) reported that supercritical water oxidation (SCWO) process significantly removed over $90 \%$ COD, TOC, SS, and BOD of real hospital wastewater after $60 \mathrm{~s}$ retention time at $25 \pm 1 \mathrm{MPa}, 450{ }^{\circ} \mathrm{C}$, and $\mathrm{H}_{2} \mathrm{O}_{2} / \mathrm{COD}$ ratio of $1: 1$. They also observed over 90 and $80 \%$ removal of phosphorus and phenol respectively at the same reaction condition. Li et al. (2020) stated that the SCWO method with $\mathrm{MnO}_{2} / \mathrm{CeO}_{2}$ catalyst showed about $98.52 \% \mathrm{COD}$ and $67.18 \%$ $\mathrm{NH}_{3}-\mathrm{N}$ removal from semi-coke wastewater at 2 min retention time, 1.3 oxidation coefficient, $25 \mathrm{MPa}$, and $550{ }^{\circ} \mathrm{C}$. Various studies on SCWO have been done over the past few decades, but their uses in industry are still in their infancy. The scale-up commercialization development of the procedure is subject to problems associated with operational cost presented by high energy input required to reach optimal reaction temperature $\left(550-750^{\circ} \mathrm{C}\right)$, although extensive research had been devoted to examine the optimization of reaction considerations like oxidant concentration, temperature, and retention time. However, very little study has been made on mixing and reactor geometry. Therefore, there is a need to conduct an extensive study on the selective oxidation of para-xylene in supercritical water under the consideration of reactor configuration to control product distribution (Pérez et al. 2016).

The formulation of metal oxide nanoparticles by supercritical water oxidation is one of the rapid green methods due to quick and continuous mixing of supercritical water stream with a cold metal salts solution stream in reactor volume. Different reactor geometries had been used to mix these two 
fluids, starting from very basic T- and Y-shaped, tube-in-tube configurations to more complex mechanical hybrid designs (Lester et al. 2018). The tube-in-tube counter-current mixing design uses the natural convection that arises from the difference of densities between supercritical water and the cold flow to creates efficient mixing between reagents (Lester et al. 2006). Using a counter-current mixing reactor for the SCWO process can offer the following advantages: (1) cool feed injection of organic compounds may prevent damage of parts and/or piercing used to heat feed due to hetero atoms that may be present in the organic compound stream causing severe corrosion to the equipment. (2) Supercritical water inside reactor contacts with organic compound by immediate warming. Fast heating may avoid charring or organic pyrolysis compounds formation. (3) Strong downstream eddies may prevent any particle accumulation on the reactor surface. (4) Oxidation rate through catalytic activities could be speedup by the synergic effect of metal oxide and organic material oxidation. (5) A mobile, large surface area is provided by nanoparticles so that any salt present in the waste stream will more likely adhere to the particle instead of reactor walls or other components.

Fenton reactions have been widely used as an advanced oxidation process for the destruction of toxic and hazardous organic chemicals. The combination of Fenton reagents (iron salt and hydrogen peroxide) produces a highly oxidative agent of hydroxyl radicals ( $\mathrm{HO}^{\prime}$ ). The organic molecules are easily attacked by hydroxyl radicals which are produced during the Fenton reactions. The present study results indicated that the addition of a small amount of dissolved iron salt to $\mathrm{H}_{2} \mathrm{O}_{2}$ solution that might increase the performance of SCWO on the degradation of acrylic acid, which play a synergistic role in the Fenton oxidation and SCWO at relatively moderate reaction temperature (Al-Atta et al. 2018).

In the present study, the combination of supercritical water oxidation (SCWO) with Fenton oxidation was used for the formulation of in situ $\mathrm{Fe}_{2} \mathrm{O}_{3}$ nano-catalyst in a countercurrent mixing reactor for the oxidation of phenol at different operational situations including, oxidant ratio, temperature, residence time, and feed concentration. Furthermore, the study also explained the effect of non-preheated and catalytic nonpreheated oxidants on the destruction of an organic compound like phenol in a counter-current mixing reactor.

\section{Materials and methods}

\section{Chemicals}

Phenol ( $\left.\geq 99 \%, \mathrm{C}_{6} \mathrm{H}_{6} \mathrm{O}\right)$ was obtained from Sigma Aldrich, USA. $\mathrm{H}_{2} \mathrm{O}_{2}(30 \% \mathrm{w} / \mathrm{v})$ was purchased from Fisher. Iron (III) nitrate nonahydrate $\left(\geq 99 \%, \mathrm{Fe}\left(\mathrm{NO}_{3}\right)_{3} \cdot 9 \mathrm{H}_{2} \mathrm{O}\right)$ got from Acros
Organics. Feed solutions of various concentrations were made from deionized and distilled water.

\section{Counter current mixing reactor setup}

The equipment setup (counter-current mixing reactor) was used to conduct the oxidation experimental work for the continuous production of nanoparticles (see Fig. 1). 316 stainless steel (Swagelok) was used to make tubing, fitting, and counter current reactor. Temperature and pressure in the system were preserved by a back-pressure regulator (BPR Pressure Tech, UK) and using Picolog software connected to a personal computer, respectively. The reaction volume was projected from the mixing point to the outlet of the reactor and found to be $1.156 \mathrm{~cm}^{3}$.

For the supercritical water oxidation experiment, an organic material solution (phenol, $\mathrm{C}_{6} \mathrm{H}_{6} \mathrm{O}$ ) was introduced to the system at a pre-set flow rate of up to $12 \mathrm{~mL} / \mathrm{min}$, using a Gilson HPLC $(30 \times)$ pump equipped with a 25 -silicon carbon (SC) pump head. The stream rolled through a check valve before entering the counter-current reactor from the inlet at the base as an upward flow without any preheating. Meanwhile, a distilled water stream that may or not contain
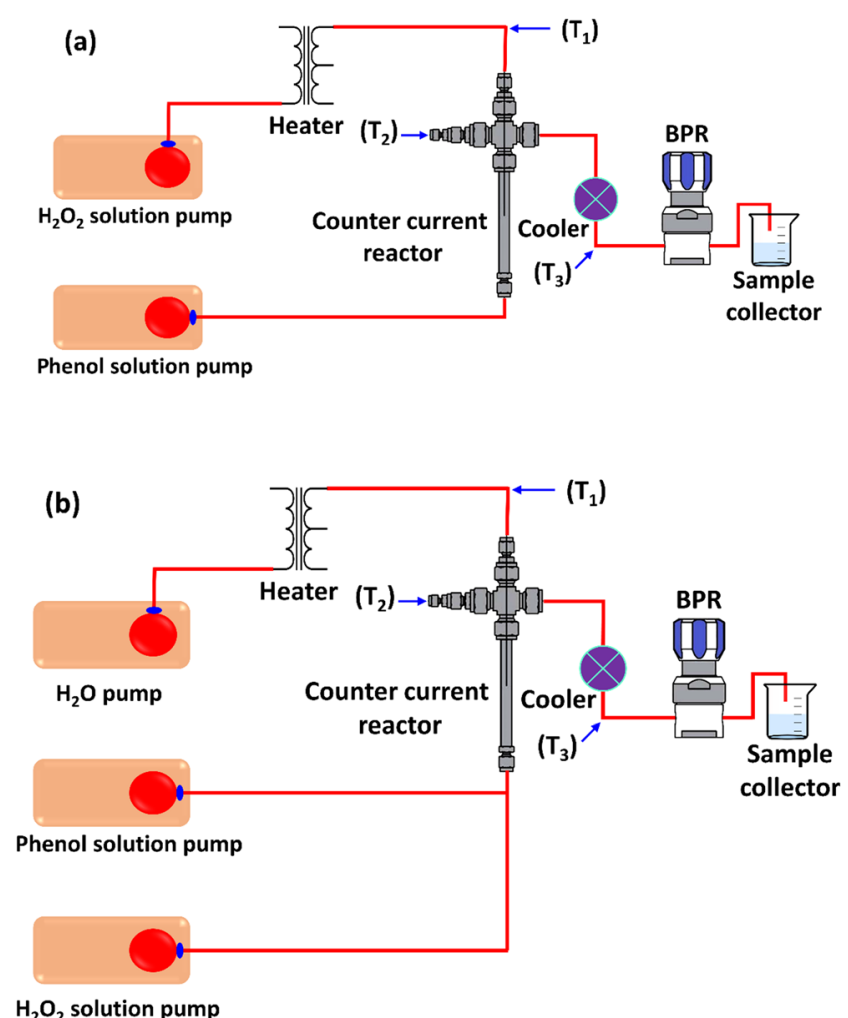

Fig. 1 The schematic diagram of counter current mixed reactor with supercritical water oxidation process for $\mathbf{a}$ preheated and $\mathbf{b}$ nonpreheated configuration. $T_{1}$ measures immediately after the heater. $T_{2}$ is the post mixed flow. $T_{3}$ is the temperature prior to the back-pressure regulator 
$\mathrm{H}_{2} \mathrm{O}_{2}$ was pumped into the system with a maximum flow of $24 \mathrm{~mL} / \mathrm{min}$ using a Gilson HPLC pump. This then proceeded to flow through a check valve before owing through a pressure relief valve and piezoelectric pressure transducer, which in turn was connected to a digital pressure monitor. The stream tossed through an analog pressure gauge before entering a $6 \mathrm{~m}$ length of $1 / 4$ " tubing coiled around a $2 \mathrm{KW}$ electric heater. A thermocouple within the heater block acted as feedback control. After the heater, the water feed flowed past a thermocouple before entering the top of the reactor as a downflow (De Silva et al. 2017).

Upon exiting the reactor, the oxidized product like oxygen and carbon dioxide developed during the oxidation process was partially cooled by a primary vertical cooling loop. The products then flowed through a Tee-shaped union at which a thermocouple was mounted on the perpendicular port, allowing the initial cooling temperature to be monitored. The product was subsequently cooled by a counter-current heat exchanger which brought the temperature down to ambient conditions approximately (Al-Atta et al. 2020, Huddle et al. 2017).

\section{Oxidant configuration assessment of phenol}

Initial trails have been made to assess whether or not the reactor configuration was suitable for the entire degradation of organic content of phenol in supercritical water in terms of oxidative efficiency. Both uncatalyzed and catalyzed $\left(\mathrm{Fe}_{2} \mathrm{O}_{3}\right)$ reactions for non-preheated and preheated oxidant configurations were performed. The experimental setup for non-preheated and preheated oxidant configurations is represented in Fig. 1. The catalytic reactions were obtained by injecting iron nitrate into the reactor as up-flow along with phenol solution. The initial experiments were conducted at $380{ }^{\circ} \mathrm{C}, 25 \mathrm{MPa}, 6.6-7.4 \mathrm{~g} / \mathrm{L}$ COD feed, $20 \mathrm{mM}$ catalyst $\left(\mathrm{Fe}\left(\mathrm{NO}_{3}\right)_{3} \cdot 9 \mathrm{H}_{2} \mathrm{O}\right), 1.5$ oxidant ratio, and $0.75 \mathrm{~s}$ residence time.

The reaction temperature was set to exceed the critical point of water which is governed by heater limitation. A short residence time was chosen because it was shown to have very little effect on the oxidation of other compounds like acrylic acid (Al-Atta et al. 2018). The results of the preliminary experiments in terms of the removal of phenol and COD are shown in Fig. 2. Although a high phenol conversion was obtained in the catalytic reaction, the COD removal of uncatalyzed and catalyzed preheated oxidant scenarios at excess oxygen was 26 and $34 \%$ respectively. Therefore, it was decided that these configurations are not suitable for the complete oxidation of phenol. Consequently, all subsequent experiments were conducted using the uncatalyzed and catalyzed non-preheated oxidant configurations.

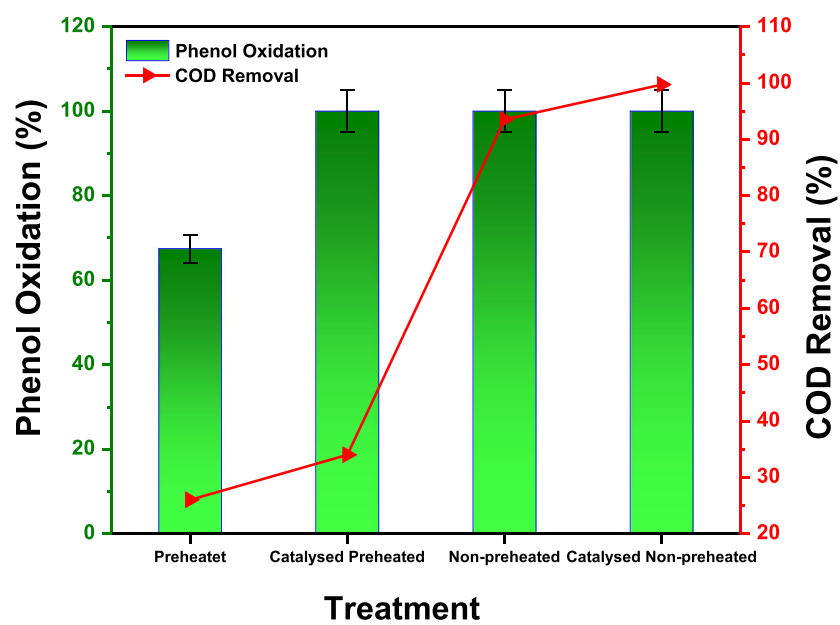

Fig. 2 Preliminary test outcomes for phenol oxidation and COD reduction at different treatments

\section{Non-preheated oxidant configuration}

The influence of different oxidant ratios $(0.0-2.0)$ was examined under the presence of different oxidant concentrations. The phenol was supplied at a constant concentration of $5 \mathrm{mM}$ at reaction conditions which corresponded to $112.2 \mathrm{mM}$ or COD of 6.6-7.4 at the feedstock. The operating conditions were maintained at $380^{\circ} \mathrm{C}, 25: 0 \mathrm{MPa}$, and a residence time of $0.75 \mathrm{~s}$. The total ion current traces (TICs) for phenol samples were also examined at an oxidant ratio of 1.0 and 1.5 .

\section{Catalytic non-preheated oxidant configuration}

Hematite $\left(\mathrm{Fe}_{2} \mathrm{O}_{3}\right)$ was chosen as a nano-catalyst for phenol oxidation in supercritical water. Iron (III) nitrate nonahydrate $\left(\mathrm{Fe}\left(\mathrm{NO}_{3}\right)_{3} \cdot 9 \mathrm{H}_{2} \mathrm{O}\right)$ was used as a precursor in the production of hematite. In a non-preheated oxidant configuration, supercritical water was mixed with a mixture of phenol, $\mathrm{Fe}\left(\mathrm{NO}_{3}\right)_{3} \cdot 9 \mathrm{H}_{2} \mathrm{O}$, and $\mathrm{H}_{2} \mathrm{O}_{2}$ solution. The in situ formed $\mathrm{Fe}_{2} \mathrm{O}_{3}$ catalyst could enhance the oxidation of organic materials. Like non-preheated oxidant configuration, the influence of oxidant ratio on the phenol and COD removal was investigated at $25 \mathrm{MPa}, 380{ }^{\circ} \mathrm{C}$, and $\mathrm{Fe}\left(\mathrm{NO}_{3}\right)_{3} \cdot 9 \mathrm{H}_{2} \mathrm{O}$ concentration of $10 \mathrm{mM}$ (Al-Atta et al. 2018).

\section{Chemical oxygen demand reduction}

Chemical oxygen demand (COD) of organic content (phenol) in water samples was observed for every trial to investigate the influence of changing various operational parameters on the removal of COD. The COD experiment included oxidizing the liquid samples' organic content under acidic conditions at $148{ }^{\circ} \mathrm{C}$ for $2 \mathrm{~h}$. Strong oxidizing agents of potassium dichromate and sulfuric acid oxidized the organic matter in the presence of silver sulfate as a catalyst. These compounds are all present in the sample cuvettes LCI400 (HACH LANGE 
LTD, Manchester, UK) used for COD measurement. Two milliliters of organic compound samples in COD cuvettes were digested in a LT 200 COD reactor. The end products were water, and carbon dioxide (Lee et al. 2011, Wu and Englehardt, 2012). As the cuvette rotated, it was measured 10 times within $5 \mathrm{~s}$ for an average value that eliminates any abnormal results. The reduction in COD was calculated using Eq. (4) (Wu \& Englehardt 2012).

$\operatorname{COD}$ reduction $(\%)=\frac{\mathrm{COD}_{\text {initial }}-\mathrm{COD}_{\text {final }}}{\mathrm{COD}_{\text {final }}} \times 100$

Two separated streams of distilled water and a known concentration of phenol and two parted streams of distilled water in a ratio of 2:1 were poured through the experimental rig at the start of operation without any preheating or pressurizing. The subsequent mixed solution flow was additionally diluted to a factor of 0.2 . Catalyst characterization. The powdered X-ray diffraction (XRD) analysis technique was applied to determine the phase composition, crystal clear size, and structure of a solid sample. The XRD analysis was examined using a Bruker D8 Advance system (Bruker AXS, Germany) through $\mathrm{Cu} \mathrm{K} \alpha$ radiation $(\lambda=1.54056 \mathrm{~A})$ in a $2 \theta$ range between $15^{\circ}$ and $75^{\circ}$. The Scherrer method, assuming Gaussian peak broadening, was used to calculate the crystallite size of metal oxide nanoparticles (Abdpour and Santos, 2020, Al-Atta et al. 2018).

Transmission Electron Microscopy (TEM; Philips Tecnai G220) analysis was used to determine particle size and morphology based on the contrast difference of the electrons that have been transmitted through. TEM analysis was used for the characterization of metal oxide nanoparticles produced through the oxidation of phenol in supercritical water. Nanometal oxides produced in water from the oxidation experiments were allowed to settle for $24 \mathrm{~h}$. A few drops of settled nanoparticles were then sampled and suspended in acetone for examination by TEM. The JEOL $2100 \mathrm{~F}$ system (FEGTEM) was used for TEM images operating at an acceleration voltage of $100 \mathrm{kV}$ (Meng et al. 2018).

\section{Results and discussion}

\section{Morphological and crystalline assessment of catalyst}

Figure 3 showed the particle size and morphology results of hematite suspension for the non-preheated and preheated oxidant configuration at a precursor concentration of $20 \mathrm{mM}$. The morphology was observed to be spherical with detectable edges. The average particle size using ImageJ software was determined as 16.20 and $26.18 \mathrm{~nm}$ for the non-preheated and preheated oxidant configuration, respectively. The average particle size was gradually decreased with increasing the $\mathrm{Fe}$
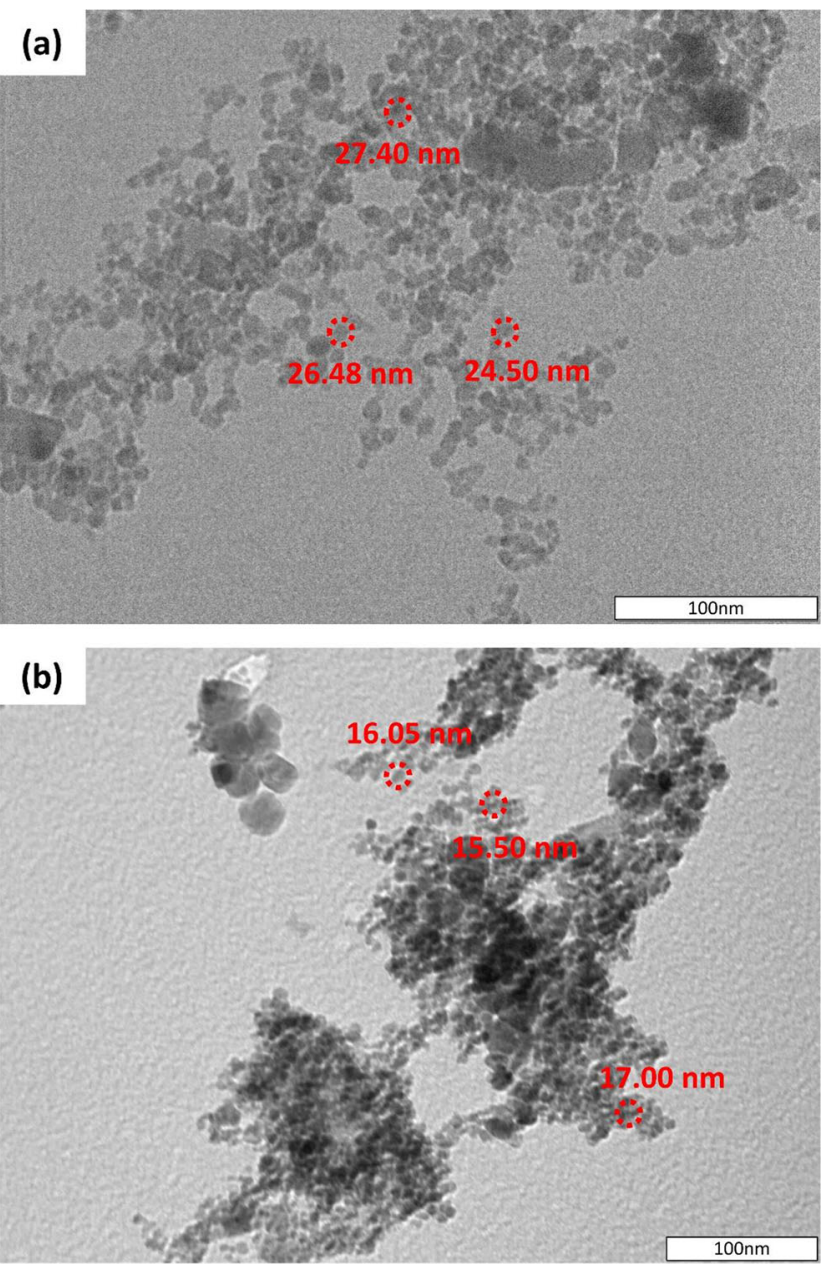

Fig. 3 TEM images of $\mathrm{Fe}_{2} \mathrm{O}_{3}$ nanoparticles obtained from a preheated oxidant and $\mathbf{b}$ non-preheated oxidant configuration

compound that was due to the molar ratio of $\mathrm{Fe} / \mathrm{O}$. Moreover, $\mathrm{Fe} / \mathrm{O}$ results in more pore volume and small pore size (Zhang et al. 2018). Salari (2019) observed that TEM images of $\mathrm{Fe}_{2} \mathrm{O}_{3}$ were regular in shape with an average size of $15 \mathrm{~nm}$.

Figure 4 reports the XRD results of hematite suspension for non-preheated and preheated oxidant configurations. XRD patterns confirmed the presence of the crystalline phase of hematite. The Scherrer equation was utilized for crystallite diameter determinations that were noted as 25.5 and $21.8 \mathrm{~nm}$ for the preheated and non-preheated oxidant configurations, respectively. Results showed the clear peaks of hematite at 2 theta values of $24,33,35.5,49.5,54,62$, and 64 for both the catalyst preheated and non-preheated oxidant configurations. There was no specific difference between hematite $\left(\mathrm{Fe}_{2} \mathrm{O}_{3}\right)$ suspension for non-preheated and preheated oxidant configuration. The present study results are in correlation with the findings of Salari (2019), who stated that diffraction peaks that appeared at $2 \theta$ values of $24,33,35,49,54,62$, and 64 related to $012,110,113,024,214$, and 300 planes respectively are due to $\mathrm{Fe}_{2} \mathrm{O}_{3}$. Similarly, Zangeneh Kamali et al., 2014 reported that XRD peaks appearing at 2 theta 

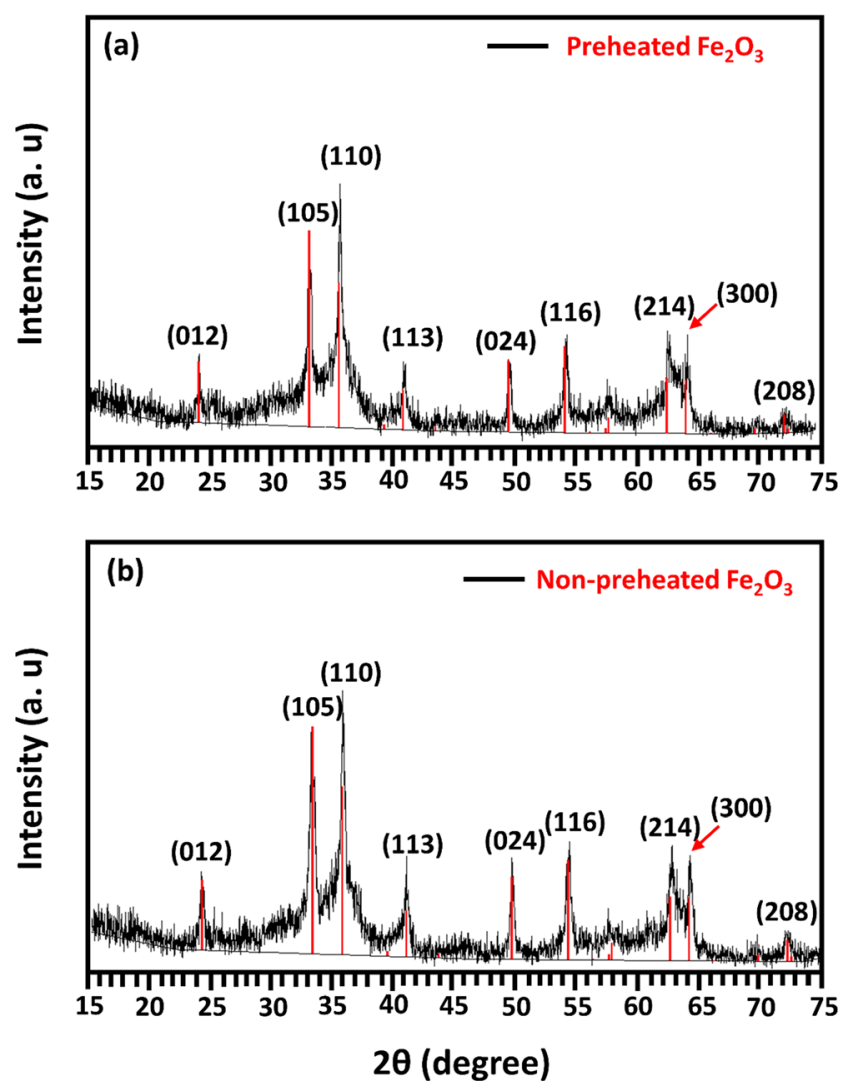

Fig. 4 XRD patterns of hematite nanoparticles for (a) preheated oxidant and (b) non-preheated oxidant scenario obtained at $380{ }^{\circ} \mathrm{C}, 25 \mathrm{MPa}$, oxidant ratio of 1.5 and $20 \mathrm{mM}$ of metal salt concentration

values of 24 (012), 35 (113), 41 (202), 54 (116), and 62 (214) are due to nanocomposites of $\alpha-\mathrm{Fe}_{2} \mathrm{O}_{3}$. The lack of any diffraction peak of $\mathrm{Fe}(\mathrm{OH})_{3}$ and $\mathrm{Fe}(\mathrm{OH})_{2}$ indicated that $\mathrm{Fe}$-based SCW had been completely converted into $\mathrm{Fe}_{2} \mathrm{O}_{3}$.

\section{COD reduction and phenol oxidation in non- preheated oxidant configuration}

The results of the effect of oxidant concentration in the nonpreheated oxidant configuration for phenol and COD are given in Fig. 5. Results showed that hydrolysis reaction has no effect on phenol degradation. However, when the concentration of oxidant increased to the stoichiometric amount, complete elimination of phenol was obtained. COD reduction increased by approximately $94 \%$ at an oxidant ratio of 2.0 , which presented a great reaction dependence on $\mathrm{HO}$ concentration. At the highest oxidant ratio, the close values of phenol and COD removal indicate that the free radical HO reduced the formation of undesirable intermediates.

Jarana and co-workers observed about $71 \%$ phenol reduction at a reactor temperature of $390{ }^{\circ} \mathrm{C}$, the pressure of 25 $\mathrm{MPa}$, the oxidant ratio of 4.8 , and residence time of $104 \mathrm{~s}$ (Jarana et al. 2010). Yan et al. (2020) stated that SCWO

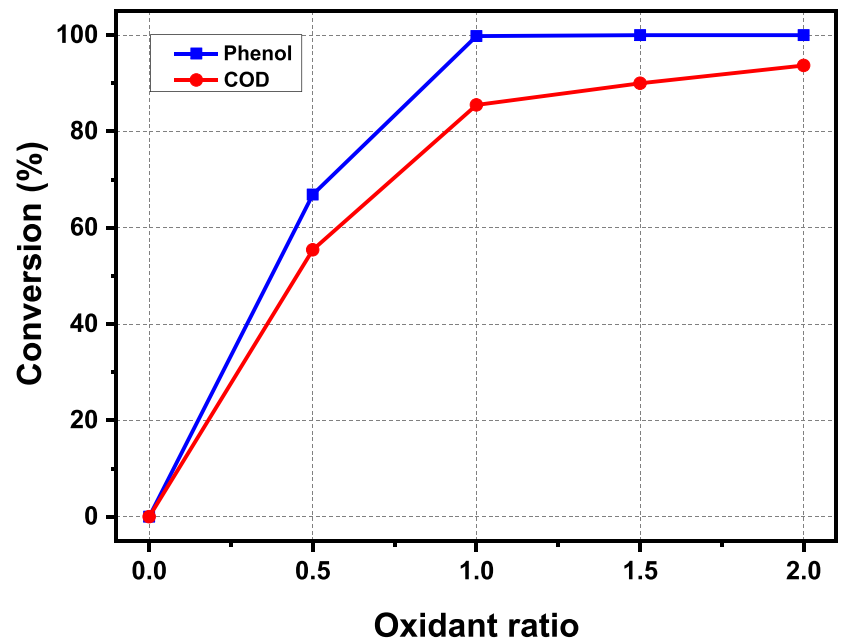

Fig. 5 Effect of oxidant ratio of non-preheated configuration on phenol oxidation and COD removal at $380^{\circ} \mathrm{C}, 25 \mathrm{MPa}$, residence time of $0.75 \mathrm{~s}$, and an initial phenol concentration of $5 \mathrm{mM}$

treatment significantly showed the COD reduction efficiency of sludge and p-tert-butylcatechol (TBC) of about 77 and $89 \%$ at oxidant ratio of 1 , and 98 and $99 \%$ at oxidant ratio of 8 , constant temperature of $550{ }^{\circ} \mathrm{C}$, the pressure of $25 \mathrm{MPa}$, and residence time of $5 \mathrm{~min}$. Similarly, Li et al. (2019) reported that SCWO treatment of dying sludge showed up to $99.80 \%$ COD reduction at a reactor temperature of $600{ }^{\circ} \mathrm{C}$, oxidation coefficient of 1.2 , the pressure of $25 \mathrm{MPa}$, and residence time of $600 \mathrm{~s}$.

Compared to other research works on the oxidation of phenol in supercritical water, the non-preheated oxidant configuration exhibits a high reduction of organic content at a relatively mild temperature and short reaction time. This is because the properties of counter-current mixing reactor provide instant and rapid heating of the organic compounds and oxidant. This fast heating of the organic compounds could avoid the formation of organic pyrolysis intermediates which are more difficult to oxidize in the reaction zone.

\section{Effect of catalyst in non-preheated configuration}

Figure 6 reports the effect oxidant ratio for the removal of COD and conversion of phenol. Results demonstrated that in the absence of an oxidant, the elimination percentage (\%) of phenol and COD was 67.4 and $29.8 \%$ respectively. By increasing the concentration of oxidant to a stoichiometric amount, the reaction approaches completion for phenol and COD (see Fig. 6). The maximum COD reduction and phenol conversion were observed to be 99.9 and $99.89 \%$ respectively with an oxidant ratio of 2.0 and reactor a temperature of 380 ${ }^{\circ} \mathrm{C}$, a pressure of $25 \mathrm{MPa}$, a residence time of $0.75 \mathrm{~s}$, initial phenol concentration of $5 \mathrm{mM}$, and an $\mathrm{Fe}\left(\mathrm{NO}_{3}\right)_{3} \cdot 9 \mathrm{H}_{2} \mathrm{O}$ concentration of $10 \mathrm{mM}$. The COD removal efficiency went up 


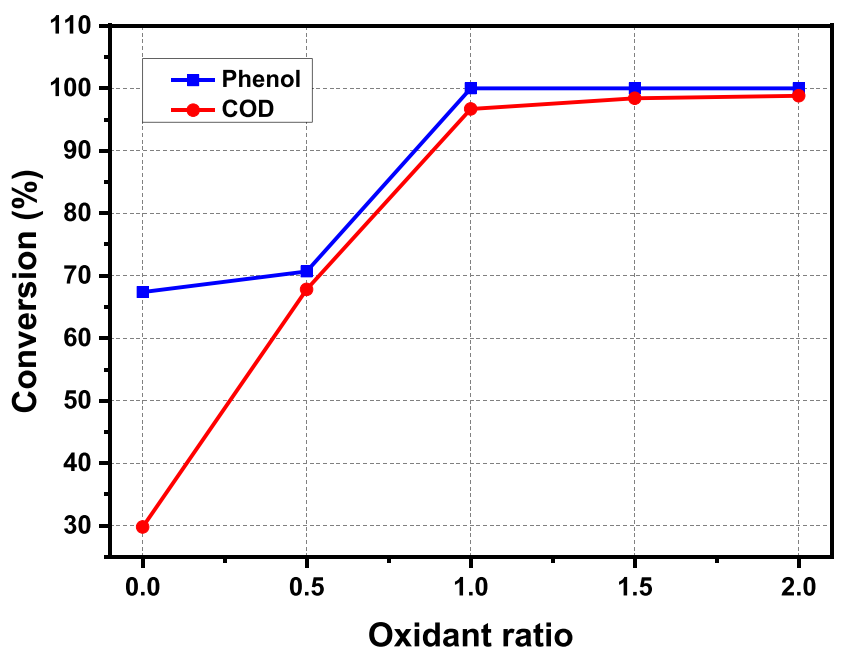

Fig. 6 Effect of oxidant ratio of catalyst non-preheated configuration on phenol oxidation and COD removal at $380^{\circ} \mathrm{C}, 25 \mathrm{MPa}$, residence time of $0.75 \mathrm{~s}$, initial phenol concentration of $5 \mathrm{mM}$, and $\mathrm{Fe}\left(\mathrm{NO}_{3}\right)_{3} \cdot 9 \mathrm{H}_{2} \mathrm{O}$ concentration of $10 \mathrm{mM}$

rapidly in the presence of salt ions, which was due to $\mathrm{Fe}^{2+}$ and $\mathrm{H}_{2} \mathrm{O}_{2}$ constitute Fenton's reagent, resulting in improved $\mathrm{H}_{2} \mathrm{O}_{2}$ decomposition into $\mathrm{HO}^{\prime}$ by having robust oxidation capacity. The findings of Ma et al. (2017) revealed that more oxygen concentration gives rise to better phenol oxidation in the catalytic reaction. They also observed almost similar values of COD removal and phenol reduction, which signifies that the catalyst lowered the formulation of detrimental intermediates.

Figure 7 shows the effect of $\mathrm{Fe}\left(\mathrm{NO}_{3}\right)_{3} \cdot 9 \mathrm{H}_{2} \mathrm{O}$ concentration on COD treatment. The operating temperature, pressure, and phenol concentration were the same as for the assessment of oxidant ratio gradients. The oxidant ratio was kept constant at 1.0. Results showed that COD removal was enhanced constantly with catalyst addition until the concentration of $20 \mathrm{mM}$. The maximum COD was observed as

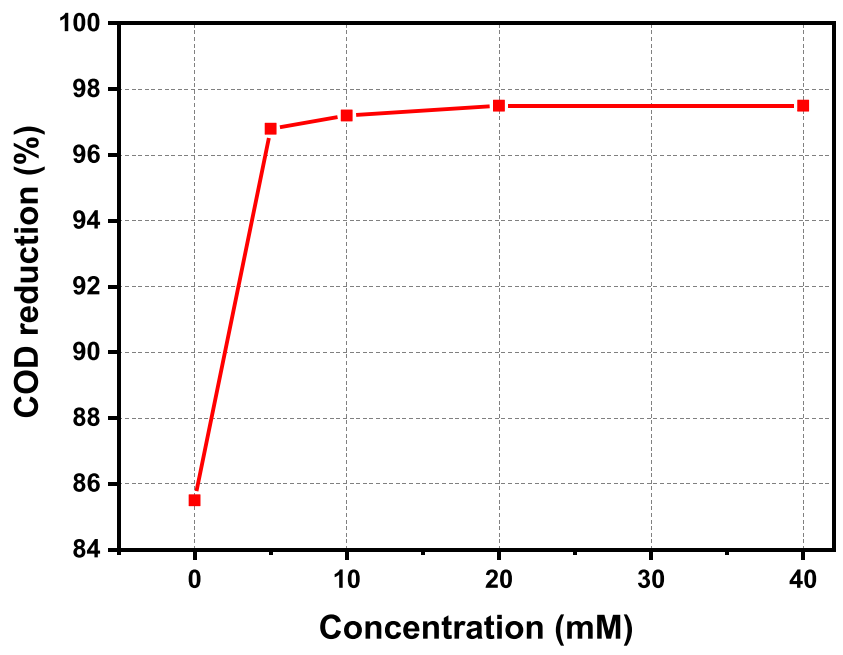

Fig. 7 The effect of in situ formed catalyst on COD removal at different concentrations using a constant temperature of $380{ }^{\circ} \mathrm{C}$, pressure of 25 $\mathrm{MPa}$, residence time of $0.75 \mathrm{~s}$, and oxidant ratio of 1.0
97.8 at phenol concentration of $5 \mathrm{mM}$, and constant temperature of $380{ }^{\circ} \mathrm{C}$, pressure of $25 \mathrm{MPa}$, residence time of $0.75 \mathrm{~s}$, and oxidant ratio of 1 . Further, it was noted that the accumulation of excessive volumes of catalyst did not significantly affect organic compound elimination. Catalyst appear to have the abolity to accelerate the reaction; however, their development is limited to a certain range of concentrations.

Jarana and co-workers (2010) observed about $99.5 \%$ phenol reduction at a reactor temperature of $390{ }^{\circ} \mathrm{C}$, pressure of $25 \mathrm{MPa}$, oxidant ratio of 4.0 , residence time of $11.4 \mathrm{~s}$, and in situ formed catalyst of $\mathrm{Cr}_{2} \mathrm{O}_{3}-\mathrm{Al}_{2} \mathrm{O}_{3}$. Li et al. (2018) examined the degradation of phenol by SCW process and observed about $80 \%$ phenol reduction efficiency at $525{ }^{\circ} \mathrm{C}$, water density of $0.098 \mathrm{~kg} / \mathrm{m}^{3}$, residence time of $60 \mathrm{~min}$, and $\mathrm{Ni} / \mathrm{CeO}_{2}$ value of $0.5 \mathrm{~g}$. Chen et al. (2020) revealed that in situ formed $\mathrm{KOH}$ catalyst by SCW treatment significantly removed up to 94.6 and $51.0 \% \mathrm{COD}$ and $\mathrm{NH}_{3}-\mathrm{N}$ of landfill leachate at a residence time of $20 \mathrm{~min}$, pressure of 23-26 MPa, and temperature of $650^{\circ} \mathrm{C}$. Similarly, Scandelai et al. (2020) reported that $\mathrm{SCWO} /$ zeolite(clinoptilolite) system significantly removed $74 \%$ COD, $98 \%$ nitrate reduction, and $81 \%$ TOC of landfill leachate at $23 \mathrm{MPa}$, and $600{ }^{\circ} \mathrm{C}$.

When evaluating the phenol catalytic oxidation rates of various researchers to those obtained in the existence of an in situ formed catalyst, a considerable rate augmentation was noted in the latter case. Greater than $99 \%$ conversion was achieved in preheated and non-preheated oxidant scenarios in the first order of magnitude shorter residence time associated with other catalytic oxidation works. The present study results indicated that the utilization of catalysts gives a smaller number of organic acid species, which suggests that catalysts are proved as efficient in the ring-opening process. However, elevated pollutant devastation proficiency might be accomplished at lower temperatures when utilizing a catalyst in the supercritical reactor system.

\section{Conclusions}

The uncatalyzed and catalyzed non-preheated oxidant configuration was chosen to perform the SCWO of phenol. Experiments were conducted at a variety of oxidant ratios and iron nitrate concentrations. It was observed that present configurations provide superior performance to a conventional SCWO process in terms of COD removal. Almost a complete removal of phenol $(99.9 \%)$ was observed at $380{ }^{\circ} \mathrm{C}$ for a residence time of less than $1 \mathrm{~s}$ in both configurations (nonpreheated and catalyst non-preheated). Reductions in COD in excess of $94 \%$ were obtained in the non-preheated oxidant scenario. Near-complete COD removals (99.9\%) were achieved at the catalytic SCWO reactions. Chromatographic information showed that only acetic acid was produced as an intermediate compound. It was determined that SCWO 
combined with in situ catalyst formation in a counter-current mixing reactor resulted in COD and phenol removal efficiencies greater than other researchers' work. Although phenol is completely oxidized in different configurations, however, some recalcitrant compounds like ammonia may require rigorous reaction conditions. Therefore, two-stage operations will be useful to increase the residence time and hence the destruction efficiency of the process. However, future research should consider the identification and quantification in detail of the products and the remaining by-products in order to build a proper reaction mechanism.

Acknowledgements The authors are grateful for the financial supports from the Engineering and Physical Sciences Research Council (EPSRC) UK.

Author contribution Ammar Al-Atta, Farooq Sher: conceptualization, methodology, software. Farooq Sher, Abu Hazafa, Ammar Al-Atta: data curation, writing - original draft preparation. Ayesha Zafar, Emina Karahmet: visualization, investigation. Edward Lester: supervision. Hafiz M.N. Iqbal, Ayesha Zafar: software, validation, reviewing, and editing; Farooq Sher; Edward Lester: funding; writing - reviewing and editing.

Data availability Not applicable.

\section{Declarations}

Ethical approval Not applicable

Consent to participate Not applicable

Consent to publish Not applicable

Competing interests The authors declare no competing interests.

Open Access This article is licensed under a Creative Commons Attribution 4.0 International License, which permits use, sharing, adaptation, distribution and reproduction in any medium or format, as long as you give appropriate credit to the original author(s) and the source, provide a link to the Creative Commons licence, and indicate if changes were made. The images or other third party material in this article are included in the article's Creative Commons licence, unless indicated otherwise in a credit line to the material. If material is not included in the article's Creative Commons licence and your intended use is not permitted by statutory regulation or exceeds the permitted use, you will need to obtain permission directly from the copyright holder. To view a copy of this licence, visit http://creativecommons.org/licenses/by/4.0/.

\section{References}

Abdpour S, Santos RM (2020) Recent advances in heterogeneous catalysis for supercritical water oxidation/gasification processes: insight into catalyst development. Process Saf. Environ. Prot. 149:169-184

Al-Atta A, Huddle T, Rodríguez YG, Mato F, García-Serna J, Cocero MJ, Gomes R, Lester E (2018) A techno-economic assessment of the potential for combining supercritical water oxidation with 'insitu'hydrothermal synthesis of nanocatalysts using a counter current mixing reactor. Chem. Eng. J. 344:431-440

Al-Atta A, Sierra-Pallares J, Huddle T, Lester E (2020) A potential cocurrent mixing reactor design for supercritical water oxidation. J. Supercrit. Fluids 158:104708

Chen Y, He Y, Jin H, Guo L (2020) Resource utilization of landfill leachate gasification in supercritical water. Chem. Eng. J. 386: 124017

De Silva CL, Garlapalli RK, Trembly JP (2017) Removal of phenol from oil/gas produced water using supercritical water treatment with $\mathrm{TiO} 2$ supported $\mathrm{MnO} 2$ ctalyst. J Environ Chem Eng 5:488-493

Fang Z, Xu CC (2014): Near-critical and supercritical water and their applications for biorefineries, 2. Springer

Huddle T, Al-Atta A, Moran S, Lester E (2017) Pseudo fluid modelling used in the design of continuous flow supercritical water oxidation reactors with improved corrosion resistance. J. Supercrit. Fluids 120: 355-365

Huelsman CM, Savage PE (2013) Reaction pathways and kinetic modeling for phenol gasification in supercritical water. J. Supercrit. Fluids 81:200-209

Jarana BG, Oneto JS, Miguélez JRP, Sanz EN, de la Ossa EJM (2010): Simulation of supercritical water oxidation with air at pilot plant scale. Int J Chem Reactor Eng 8

Kıpçak E, Akgün M (2012) Oxidative gasification of olive mill wastewater as a biomass source in supercritical water: effects on gasification yield and biofuel composition. J. Supercrit. Fluids 69:57-63

Lee E, Lee H, Kim Y, Sohn K, Lee K (2011) Hydrogen peroxide interference in chemical oxygen demand during ozone based advanced oxidation of anaerobically digested livestock wastewater. Int. J. Environ. Sci. Technol. 8:381-388

Lester E, Blood P, Denyer J, Giddings D, Azzopardi B, Poliakoff M (2006) Reaction engineering: the supercritical water hydrothermal synthesis of nano-particles. J. Supercrit. Fluids 37:209-214

Lester E, Dunne P, Chen Y, Al-Atta A (2018): The engineering of continuous hydrothermal/solvothermal synthesis of nanomaterials, Supercritical and Other High-pressure Solvent Systems, pp. 416448

Li B, Zhang B, Guan Q, Chen S, Ning P (2018) Activity of Ni/ $\mathrm{CeO}_{2}$ catalyst for gasification of phenol in supercritical water. Int. J. Hydrog. Energy 43:19010-19018

Li J, Wang S, Jiang Z, Yang C, Xu H (2019) Supercritical water oxidation of dyeing sludge. Earth Environ Sci 233:052004

Li J, Wang S, Li Y, Wang L, Xu T, Zhang Y, Jiang Z (2020) Supercritical water oxidation of semi-coke wastewater: effects of operating parameters, reaction mechanism and process enhancement. Sci. Total Environ. 710:134396

Lin H, Ma X (2012) Simulation of co-incineration of sewage sludge with municipal solid waste in a grate furnace incinerator. Waste Manag. 32:561-567

Ma C, Wen Y, Yue Q, Li A, Fu J, Zhang N, Gai H, Zheng J, Chen BH (2017)Oxygen-vacancy-promoted catalytic wet air oxidation of phenol from $\mathrm{MnOx}-\mathrm{CeO}_{2}$. RSC Adv. 7:27079-27088

Meng Q, Liu J, Weng X, Sun P, Darr JA, Wu Z (2018) In situ valence modification of $\mathrm{Pd} / \mathrm{NiOnano-catalysts} \mathrm{in} \mathrm{supercritical} \mathrm{water} \mathrm{towards}$ toluene oxidation. Catalysis Sci Technol 8:1858-1866

Nadjiba B, Nawel O, Hassen MA (2017) Modeling and optimization of phenol hydrothermal oxidation in supercritical water. Int. J. Hydrog. Energy 42:12926-12932

Pérez E, Thomas ML, Housley D, Hamley PA, Fraga-Dubreuil J, Li J, Lester E, Poliakoff M (2016) Selective aerobic oxidation of paraxylene in sub-and supercritical water. Part 3: effects of geometry and mixing in laboratory scale continuous reactors. RSC Adv 6:11289 11294 
Pillai IMS, Gupta AK (2016) Anodic oxidation of coke oven wastewater: multiparameter optimization for simultaneous removal of cyanide, COD and phenol. J. Environ. Manag. 176:45-53

Ren L-F, Chen R, Zhang X, Shao J, He Y (2017) Phenol biodegradation and microbial community dynamics in extractive membrane bioreactor (EMBR) for phenol-laden saline wastewater. Bioresour. Technol. 244:1121-1128

Ren L-F, Adeel M, Li J, Xu C, Xu Z, Zhang X, Shao J, He Y (2018) Phenol separation from phenol-laden saline wastewater by membrane aromatic recovery system-like membrane contactor using superhydrophobic/organophilic electrospun PDMS/PMMA membrane. Water Res. 135:31-43

Salari H (2019) Kinetics and mechanism of enhanced photocatalytic activity under visible light irradiation using $\mathrm{Cr}_{2} \mathrm{O}_{3} / \mathrm{Fe}_{2} \mathrm{O}_{3}$ nanostructure derived from bimetallic metal organic framework. J Environ Chem Eng 7:103092

Scandelai APJ, Zotesso JP, Jegatheesan V, Cardozo-Filho L, Tavares CRG (2020) Intensification of supercritical water oxidation (ScWO) process for landfill leachate treatment through ion exchange with zeolite. Waste Manag. 101:259-267

Top S, Akgün M, Kıpçak E, Bilgili MS (2020) Treatment of hospital wastewater by supercritical water oxidation process. Water Res. $185: 116279$

Wu T, Englehardt JD (2012) A new method for removal of hydrogen peroxide interference in the analysis of chemical oxygen demand. Environ. Sci. Technol. 46:2291-2298

Xu T, Wang S, Li Y, Zhang J, Li J, Zhang Y, Yang C (2020) Optimization and mechanism study on destruction of the simulated waste ion-exchange resin from the nuclear industry in supercritical water. Ind. Eng. Chem. Res. 59:18269-18279

Yan Z, Örmeci B, Han Y, Zhang J (2020) Supercritical water oxidation for treatment of wastewater sludge and recalcitrant organic contaminants. Environ. Technol. Innov. 100728:100728

Zangeneh Kamali K, Alagarsamy P, Huang NM, Ong BH, Lim HN (2014) Hematite nanoparticles-modified electrode based electrochemical sensing platform for dopamine. Sci World J

Zhang H, Zhang X, Ding L, Gong M, Su Y, Wang S (2019) Polymerization and oxidation of phenols in supercritical water. Water Sci. Technol. 80:620-633

Zhang H, Zhang X, Ding L (2020a) Partial oxidation of phenol in supercritical water with $\mathrm{NaOH}$ and $\mathrm{H} 2 \mathrm{O} 2$ : hydrogen production and polymer formation. Sci. Total Environ. 722:137985

Zhang T, Wang H, Zhou B, Ji X, Wang H, Du A (2018)One-dimension diffusion preparation of concentration-gradient $\mathrm{Fe}_{2} \mathrm{O}_{3} / \mathrm{SiO}_{2}$ aerogel. Molecules 23:1502

Zhang Y, Wang S, Li Y, Zhang J, Xu D, Yang C, Yang J, Li J, Xu T (2020b) Inorganic salts in sub-/supercritical water - part A: behavior characteristics and mechanisms. Desalination 114674:114674

Zhao G, Li N, Li B, Li W, Liu Y, Chai T (2020) ANN model for predicting acrylonitrile wastewater degradation in supercritical water oxidation. Sci. Total Environ. 704:135336

Publisher's note Springer Nature remains neutral with regard to jurisdictional claims in published maps and institutional affiliations. 